\title{
Multi-model comparison of Swiss decarbonization scenarios
}

\author{
Florian Landis ${ }^{1}$ (D), Adriana Marcucci ${ }^{1 *}$, Sebastian Rausch ${ }^{1}$, Ramachandran Kannan² and Lucas Bretschger ${ }^{1}$
}

\begin{abstract}
Collaborating under the Swiss Energy Modeling Platform (SEMP), five modeling teams (employing an energy systems model and four macroeconomic models with a focus on energy) have carried out a multi-model comparison to assess the economic and technological consequences of reaching emission reduction targets for 2050 in the context of Switzerland. We consider different designs of carbon taxes to compare their economic cost: economy-wide or sector-specific carbon taxes with or without an emission trading system (ETS) in place. All models find that the climate targets can be reached at modest welfare reductions of $0.15-0.37 \%$ (if targeting 1.5 tonnes of $\mathrm{CO}_{2}$ per capita) or $0.24-0.48 \%$ (if targeting 1.0 tonnes per capita) compared to a business-as-usual scenario in which the emission level of 1.5 tonnes per capita is exceeded by $83-137 \%$. In contradiction to the additional target of reducing Swiss electricity use, most models find it cost-effective to replace some of the energy supplied by fossil fuels by electricity and thus do not recommend a decrease in electricity use.

Most models find that a uniform carbon tax is the most efficient instrument to achieve the emission reduction targets. Those models with a detailed representation of pre-existing mineral oil taxes find that in early periods of climate policy, taxing emission from transport fuels at lower rates than other emissions may be cost-efficient. This effect vanishes as the stringency of targets and thus $\mathrm{CO}_{2}$ taxes increase over time.
\end{abstract}

Keywords: Climate policy, Switzerland, Model comparison, Energy system modeling, Computable general equilibrium, Cost-effectiveness

\section{Introduction}

In concert with other nations under the Paris climate agreement, Switzerland has set itself targets for greenhouse gas (GHG) emission reduction. Even superficial comparisons between current patterns of energy use (with the related emissions) and the required emission reduction requirements for the long run make it clear that a major reduction in energy use and/or restructuring of the energy sector is necessary to meet the targets. Such a transformation will not come without cost, and economists have been looking at how to reach the targets in the optimal way for a while now. Several studies using numerical models have been carried out in order to analyze the technological and economic cost of Swiss climate targets and to compare different policy options for reaching them (see, e.g., Marcucci and Turton (2012);

*Correspondence: adriana.marcucci@sccer-soe.ethz.ch

${ }^{1}$ Center of Economic Research, ETH Zurich, Zürichbergstrasse 18, 8092, Zurich, Switzerland

Full list of author information is available at the end of the article
Sceia et al. (2012); Bretschger and Lin (2017); Bretschger et al. (2011); Landis et al. (2018); Böhringer and Müller (2014); Kannan and Turton (2016); Ecoplan (2012); Prog$\operatorname{nos}(2012))$.

Comparing the results of the different studies, one inevitably finds differences in results and it remains unclear if these differences between studies arise from analyzing somewhat different problems or if they reflect uncertainty about future economic development or even disagreement about the proper representation of technological options for meeting the targets. Table 1 , for example, shows different results for welfare losses according to different studies. The table also lists a selection of key features of the referenced studies such as time horizon, policy target, and reference scenario from which welfare impacts are measured. Clearly, there are a variety of targets and reference scenarios, and the question remains open if the found variation of welfare impacts 
Table 1 Welfare results of different studies on Swiss climate policy

\begin{tabular}{|c|c|c|c|c|}
\hline Publication & Reference scenario & Year & GHG emissions target & Welfare change (percentage from reference) \\
\hline \multirow[t]{3}{*}{ Marcucci and Turton (2012) } & \multirow[t]{3}{*}{ No-policy } & 2030 & 400 ppm & -2 \\
\hline & & 2040 & 400 ppm & -1.5 \\
\hline & & 2080 & 400 ppm & -0.8 \\
\hline Sceia et al. $(2012)^{b}$ & Continuation of & 2020 & $-21 \%$ w.r.t. 1990 & -0.33 \\
\hline
\end{tabular}

\begin{tabular}{|c|c|c|c|c|}
\hline \multicolumn{5}{|c|}{ existing } \\
\hline & & 2030 & - 31\% w.r.t. 1990 & -0.34 \\
\hline & & 2020 & - 30\% w.r.t. 1990 & -0.49 \\
\hline & & 2030 & - 45\% w.r.t. 1990 & -0.47 \\
\hline Bretschger and Lin (2017) & No-policy & 2050 & $-65 \%$ w.r.t. 2010 & -1.58 \\
\hline \multirow[t]{2}{*}{ Bretschger et al. (2011) ${ }^{\mathrm{d}}$} & No-policy & 2020 & - 30\% w.r.t. 1990 & -1 \\
\hline & & 2050 & - 80\% w.r.t. 1990 & -4.5 \\
\hline \multirow[t]{3}{*}{ Karydas and Zhang $(2017)^{\mathrm{c}}$} & No-policy & 2050 & - 20\% w.r.t. 2010 & -1.33 \\
\hline & & & - 40\% w.r.t. 2010 & -2.25 \\
\hline & & & - 60\% w.r.t. 2010 & -4.00 \\
\hline \multirow[t]{5}{*}{ Landis et al. (2018) } & Continuation of & 2030 & - 30\% w.r.t. 1990 & -0.15 \\
\hline & already decided & & & \\
\hline & climate policies & & & \\
\hline & & 2030 & - 40\% w.r.t. 1990 & -0.5 \\
\hline & & 2030 & - 50\% w.r.t. 1990 & -1.25 \\
\hline \multirow[t]{3}{*}{ Böhringer and Müller (2014)f } & Continuation of & 2050 & $-63 \%$ w.r.t. BAU & -1.0 \\
\hline & already decided & & & to \\
\hline & climate policies & & & -0.4 \\
\hline \multicolumn{5}{|c|}{$\begin{array}{l}\text { aPolicy target is to phase out global GHG emissions such that atmospheric concentrations do not exceed } 400 \text { parts per million (ppm). The model assumes a global social } \\
\text { planner to distribute abatement efforts efficiently across technologies, time, and space. The "welfare" measure used is GDP } \\
\text { bWe report results for the scenario where emission reductions outside Switzerland that are payed for by Swiss sectors count toward the target. Climate policies in reference } \\
\text { scenario are as of } 2007 \text {. The welfare measure is household consumption } \\
\text { 'The study considers changes in intertemporal utility of consumption after } 2010 \\
\text { dThe study reports both consumption reductions in } 2050 \text { and changes in intertemporal welfare. Here, we list changes in annual consumption. Intertemporal welfare is } \\
\text { reduced by } 2.6 \% \\
\text { eThe welfare measure is real household consumption } \\
\text { fIn the reference scenario, per capita } \mathrm{CO}_{2} \text { emissions reach } 3.8 \text { tonnes and the GHG emission target corresponds to } 1.5 \text { tonnes per capita. Real household consumption is the } \\
\text { welfare measure }\end{array}$} \\
\hline
\end{tabular}

results from those different assumptions or from the different models' assumptions about technological options for emission abatement.

This overview paper and the special issue at hand shall contribute to resolving this ambiguity. By running several models using synchronized reference and policy scenarios, we explore to what extent agreement about outcomes exists and where model results differ. To this end, the Swiss Energy Modeling Platform (SEMP) ${ }^{1}$ coordinated five Swiss modeling teams in evaluating policy options for reaching Switzerland's climate policy targets for $2050^{2}$.

\footnotetext{
${ }^{1}$ More about SEMP can be found on the website http://simlab.ethz.ch/semp. php

${ }^{2}$ This type of coordinated model activity has previously been employed by Stanford University's Energy Modeling Forum (EMF; see https://emf.stanford. $\mathrm{edu} /$ ) and the Integrated Assessment Modeling Consortium (IAMC; see http:// www.globalchange.umd.edu/iamc/) in the context of US and global energy
}

SEMP defined common reference scenarios, prescribing trends for population growth and economic growth, as well as energy demand and energy prices on the global market. For the policy scenarios, SEMP defined both emission reduction targets and different policy packages employed to meet the targets.

Each of the participating model types draws on different fields of knowledge, is routed in different modeling paradigms, and therefore focuses on specific aspects of the economy, the technology, and the society when analyzing energy and climate policy options. Thus, the goal of SEMP is to analyze common trends and differences

and climate policy as well as in different European model comparison projects, see for instance Limits (Kriegler et al., 2013) and Ampere (Kriegler et al., 2015). 
(driven by model-specific assumptions or model characteristics) in the scenario results, thus highlighting the more robust insights from energy and climate modeling. Besides highlighting to what extent results of modeling exercises may depend on the model (type) employed, close collaboration between modeling teams may allow modelers to learn which modeling decisions have crucial impacts on results and ideally may motivate further research for better understanding of certain features of models (Huntington et al., 1982).

For this study, we use two types of models: topdown computable general equilibrium models and a technology-rich bottom-up energy system model. The complementarity of the two methodologies allows us to provide insights on how alternative designs of the Swiss climate policy would impact different aspects of the economy and the energy system.

For designing the SEMP policy targets, we looked to the Swiss Nationally Determined Contribution (NDC) to the Paris Agreement, ratified in October 2017. Its stated goal is to reduce greenhouse gas (GHG) emissions in 2030 by $50 \%$ compared to 1990 levels $^{3}$. The Federal Council has also defined a long-term objective in the context of the two-degree pathway. This target is a reduction of GHG emissions by $70-85 \%$ by 2050 relative to 1990 levels (between 1 and 2 tonnes of $\mathrm{CO}_{2}$ equivalent $\left(\mathrm{CO}_{2} \mathrm{e}\right)$ per capita). The Swiss 2050 Energy Strategy, which was approved by public vote in May 2017 and resulted in the New Energy act, has three strategic objectives: increasing energy efficiency (to reduce energy use), increasing the use of renewable-based energy sources, and the withdrawal from nuclear energy (Swiss Federal Assembly, 2018; Swiss Federal Council, 2013a; Prognos, 2012). In this model comparison, we aim at assessing the consequences on the energy system and the economy of achieving two 2050 carbon emission targets: 1.5 and 1.0 tonnes $\mathrm{CO}_{2}$ $\left(\mathrm{tCO}_{2}\right)$ per capita, which correspond to 70 and $80 \%$ reductions compared to 2010 levels. We then compare impacts on the energy system to the targets in the 2050 Energy Strategy in order to judge to what extent these targets can be motivated by (arguably) cost-effective climate policy.

A good candidate for cost-effective climate policy is the uniform carbon $\operatorname{tax}^{4}$. Therefore, we assess the cost of reaching Swiss climate targets for 2050 using different carbon pricing options including economy-wide uniform carbon taxes and tax designs in line with recent

\footnotetext{
${ }^{3}$ See "Switzerland's intended nationally determined contribution (INDC) and clarifying information" by the Federal Office for the Environment (BAFU):

https://www.newsd.admin.ch/newsd/message/attachments/38517.pdf

${ }^{4}$ The price signal that the uniform carbon tax sends helps distribute emission reductions cost-effectively in economies with undistorted markets and perfect competition. If markets are distorted by pre-existing taxes, deviations from the uniform tax may be in order (Bovenberg and Goulder, 1996; Landis et al., 2018). Böhringer et al. (2019) argue that the Swiss emission reduction targets can be reached at significantly lower cost if carbon taxes are increased than by implementing more stringent forms of other currently implemented policies.
}

proposals ${ }^{5}$. Recent proposals include the Swiss emission trading scheme (ETS) in its current form and in a form where it is coupled to the EU's ETS. For non-ETS sectors, emissions may be priced by a uniform carbon tax or by a carbon tax that differentiates between transport and heating fuels.

We find that the reductions in total energy use envisaged by the Swiss Energy Strategy are in line with the recommendations made by the models. When it comes to electricity use, however, most model results suggest an increase in total electricity use as a cost-effective way of satisfying energy demand without increasing emissions, which contradicts the reduction targets in the New Energy Act. By comparing results from general equilibrium models (clearing market for annual electricity demand) with an energy system model (modeling electricity markets with hourly resolution), we verify that the assumptions about the total availability of renewable energy sources throughout the year of the former are realistic. In our policy scenarios, we explore different suggested ways of differentiating carbon taxes by fuels or sectors. For the 2050 targets, the models unanimously recommend a uniform carbon tax for cost-effectively reaching them. In earlier years, as emission reductions are not as stringent yet, tax differentiation may have some moderate benefits.

This paper is organized as follows: Section 2 describes the studied scenarios. Section 3 presents the used models. Sections 4 and 5 present and discuss the consequences on the energy system and economy of current policies and achieving long-term climate targets in Switzerland. Section 6 analyzes the consequences of alternative steering-based policies, and the last section concludes.

\section{Scenarios}

The Swiss Nationally Determined Contribution (NDC) to the Paris Agreement, ratified in October 2017, is to reduce greenhouse gas (GHG) emissions in 2030 by $50 \%$ compared to 1990 levels $^{3}$. The Federal Council has also defined a long-term objective in the context of the twodegree pathway. This target is a reduction of GHG emissions by $70-85 \%$ by 2050 relative to 1990 levels (between 1 and 2 tonnes of $\mathrm{CO}_{2}$ e per capita). In the SEMP study, we evaluate two $\mathrm{CO}_{2}$-only targets consistent with the reduction of GHG emissions to $1.0 \mathrm{tCO}_{2} \mathrm{e}$ and $1.5 \mathrm{tCO}_{2} \mathrm{e}$ per capita. Given our harmonizing assumptions about the Swiss population in 2050 (see Table 2), these targets correspond to 70 and $80 \%$ GHG emission reductions by

\footnotetext{
${ }^{5} \mathrm{~A}$ proposal for climate and energy policies to move away from subsidizing renewable energies and energy efficiency measures to steering-based policies was presented under the name Klima- und Energielenkungssystem (KELS). Price signals to consumers and producing industries were supposed to achieve the carbon abatement goals but also steer electricity demand (Federal Council 2015). The parliament did not agree to make the according changes to the constitution, but carbon taxes remain the instrument that is likely to be ramped up in order to meet Swiss emission targets (see https://www. parlament.ch/de/ratsbetrieb/suche- curia-vista/geschaeft?AffairId=20150072).
} 
2050 relative to 1990 levels. In estimating these targets, we assume that (1) the reduction in $\mathrm{CO}_{2}$ is proportional to the reduction in total GHG emissions and (2) the targets indicated by the Federal Council are to be met domestically. Therefore, the $2050 \mathrm{CO}_{2}$-only targets translate to $12.9 \mathrm{MtCO}_{2}$ and $8 \mathrm{MtCO}_{2}$ for the 1.5 and $1.0 \mathrm{tCO}_{2}$ p.c., respectively.

For reaching the climate targets, we consider three alternative designs of $\mathrm{CO}_{2}$ pricing. Each scenario is implemented by imposing a cap on the economy-wide carbon emissions:

1. Economy-wide $\mathrm{CO}_{2}$ tax: Corresponds to a uniform carbon tax on all fossil energy across the whole economy. This represents the textbook policy advice, and in an economy without distortions and with rational agents, this is the most cost-effective policy for reaching a given target.

2. ETS and uniform $\mathrm{CO}_{2}$ tax: In accordance with currently implemented and planned policies, the emissions of firms of certain sectors are regulated by an emission trading system (ETS). The rate at which the cap of the ETS is reduced is synchronized with the ETS of the EU (i.e., 1.74\% decrease per annum). Non-ETS sector emissions are priced by a uniform carbon tax.

3. ETS and differentiated $\mathrm{CO}_{2}$ tax: Non-ETS sector emissions are priced by a carbon tax that differentiates between transport and heating fuels. The current political discussion reveals a preference for not having a $\mathrm{CO}_{2}$ tax on transport fuels. This is motivated by the pre-existence of considerable mineral oil tax rates on transport fuels. In order to compare the cost-effectiveness of a uniform $\mathrm{CO}_{2}$ tax on all fossil fuels with that of a tax system with a lower $\mathrm{CO}_{2}$ tax on transport fuels than on heating fuels, additional policy scenarios with differentiated $\mathrm{CO}_{2}$ taxes by fuel type are introduced. The $\mathrm{CO}_{2}$ taxes on heating and transport fuels (tax heating $_{\text {and }}$ tax $\left.x_{\text {transport }}\right)$ are related by:

$$
\text { tax }_{\text {transport }}=0.25 \times \text { tax }_{\text {heating }}
$$

The tax rate on mineral oils is assumed to remain at current levels, i.e., at CHF 0.7312 per liter for gasoline and CHF 0.7587 per liter for diesel oil.

The results of the policy scenarios are all compared to a business-as-usual (BAU) scenario where current climate policies are assumed to be continued, but not intensified. The design of climate policy is assumed such that the revenue of the Swiss government (in real terms) remains constant across different baseline and policy scenarios for any given year. The carbon tax revenue (net of what is needed to leave real government spending unchanged) is redistributed via per-capita lump-sum transfers. Table 3 summarizes the scenarios.

\subsection{Harmonizing assumptions}

An important part of the SEMP study is the harmonization of the external drivers across models to increase the comparability of the modeling results. Table 2 presents the population and prices of energy carriers used in the study. In 2012, after the nuclear accident in Fukushima, Switzerland decided to phase out nuclear power. This implies that no new nuclear power plants will be built and the current nuclear plants can continue to operate as long as they are safe. In the SEMP study, we assume an operational lifetime of 50 years from the commissioning year; hence, nuclear power is phased out by 2034 .

\section{Models}

This paper compares the results from five energyeconomy models that participated in the SEMP model intercomparison project. All models include Switzerland as one or the only region. The set of models can be broadly grouped into two distinct model categories: general equilibrium models and energy system models (see Table 4).

Table 2 Harmonizing assumptions

\begin{tabular}{|c|c|c|c|c|c|}
\hline & 2010 & 2020 & 2035 & 2050 & Reference \\
\hline Population (million) & 7.8 & 8.7 & 9.8 & 10.3 & BFS Scenario A-00-2015 (BFS 2015) \\
\hline Working population (million full time eq.) & 3.85 & 4.31 & 4.58 & 4.63 & BFS Scenario A-00-2015 (BFS 2015) \\
\hline Oil price (2010\$/barrel) & 78 & 105 & 120 & 129 & 4DS scenario, IEA (2015) \\
\hline Gas price $(2010 \$ / M B t u)$ & 7.5 & 10.4 & 11.7 & 12.4 & 4DS scenario, IEA (2015) \\
\hline Cooling degree days ${ }^{\mathrm{a}}$ & 120 & & 235 & 280 & "Klima Waermer" scenario, Prognos (2012) pp. 80-81 \\
\hline Heating degree days ${ }^{\mathrm{a}}$ & 3586 & & 3002 & 2831 & "Klima Waermer" scenario, Prognos (2012) pp. 80-81 \\
\hline Cap on emissions from ETS sectors (relative to 2013) & & 0.88 & 0.68 & 0.52 & EU ETS yearly reduction \\
\hline
\end{tabular}

a Underlying assumption for 2035 : a temperature increase in the winter months September-May of $1^{\circ} \mathrm{C}$ and in the summer months June-August of $2^{\circ} \mathrm{C}$; for 2050 : a temperature increase in the winter months October-April of $1.5^{\circ} \mathrm{C}$, in the summer months June-August of $2.5^{\circ} \mathrm{C}$, and in May and September of $2^{\circ} \mathrm{C}$

${ }^{\mathrm{b}}$ The cap is used in all scenarios except those with an economy-wide tax (1.5_uni and 1.0_uni). The cap is computed using a yearly reduction factor of 1.74\% used in the EU ETS until 2020 
Table 3 Analyzed scenarios: climate goals and alternative policies

\begin{tabular}{lll}
\hline Description & \multicolumn{2}{c}{ Name } \\
\hline Current climate change mitigation policies & \multicolumn{2}{c}{ BAU } \\
Climate targets (tonne $\mathrm{CO}_{2}$ per capita): & $1.5 \mathrm{tCO}_{2}$ p.c. & $1.0 \mathrm{tCO}_{2}$ p.c. \\
Economy-wide $\mathrm{CO}_{2}$ tax & $1.5 \_$uni & 1.0_uni ${ }^{\mathrm{a}}$ \\
ETS and uniform $\mathrm{CO}_{2}$ tax & 1.5ETS_uni & 1.0ETS_uni \\
ETS and differentiated $\mathrm{CO}_{2}$ tax ${ }^{\mathrm{b}, \mathrm{c}}$ & 1.5ETS_diff & 1.0ETS_diff
\end{tabular}

aThe 1.0_uni scenario was not analyzed by the STEM model because of limited mitigation options in the model. It is assumed that the renewable potentials are limited and CCS is unavailable. Neither purchase of emission credit nor import of zero carbon energy commodities are considered

' This scenario is not implemented by the STEM model, given its characteristics of a bottom-up model, which does not represent the whole economy

'This scenario is not implemented by the CEPE-316 model because the model does not make a distinction between heating and transport oil

The general equilibrium models comprehensively represent the interactions between the energy system and the overall economy and are able to quantify the macroeconomic implications of alternative energy and climate policies, but they usually have a limited technological representation of the energy system. The partial equilibrium energy system models usually represent a wide portfolio of energy technologies and options for emissions reduction, but they do not endogenously model the evolution of economic activity and other macroeconomic indicators and thus use a more narrow concept of measuring economic cost.

All CGE models without a detailed representation of other regions and the STEM model consider Switzerland as an small open economy, therefore taking world market prices of traded commodities as given. They assume that the rest of the world is not changing climate policy between Swiss policy scenarios and that global market prices remain unchanged if Switzerland implements different emission target. The two global models CEPE-316 and GEMINI-E3 model regional demand for imports and supply of exports just the way they are represented for Switzerland, and thus, relative prices at which traded goods are exchanged are endogenous in principle. No country apart from Switzerland is assumed to change their climate policy across scenarios, and thus, change in global market prices will be limited to the trade effects of changes in Swiss climate policy.

In terms of modeling dynamics, the CITE model solves the intertemporal equilibrium which results in maximized intertemporal consumer welfare from the point of view of households facing market prices and government policies. Capital markets between periods ensure that forwardlooking investors with perfect foresight anticipate impacts of future policies on capital rents and choose investment volumes accordingly. STEM is a dynamic optimization model for supplying energy for exogenously defined amounts of energy services at lowest cost. Similarly to
CITE, it assumes competitive markets and perfect information on future demands, technologies, energy prices, etc. without considering any uncertainties around them.

In recursive dynamic models such as CEPE-316 and GEMINI-E3, investors observe current commodity prices and capital rents and decide where to invest based on this and their constant savings rate. Agents in this model are assumed to be ignorant about future developments and may miss opportunities to adjust investments according to future needs arising from important policy shocks. In policy scenarios in which the investment good becomes relatively (relative to income) more expensive, real investments and thus availability of capital in future periods will decrease. The resulting welfare are a lower bound for what may be achieved in a perfect foresight model, as the additional investment adjustments that agents with perfect foresight would make would surely serve to increase the agents' welfare ${ }^{6}$.

CEPE-HH follows yet a different approach by keeping real savings constant. In this model, the availability of capital in the following periods does not depend on scenario outcomes. Similar to recursive dynamic models with a constant savings rate, results for welfare losses should be interpreted as upper bounds as investors with perfect foresight may find different investment patterns that increase welfare more in the target scenarios than in BAU.

In the following, we will give short descriptions of the individual models. We refer the reader to the contributions of modeling teams to this paper collection (special issue) for more detailed model descriptions.

\subsection{CEPE-HH}

CEPE-HH (Computable General Equilibrium Model for Energy Policy and Economics - with a focus on household consumption) is a static small open economy model of the Swiss economy (Landis et al., 2018; Landis, 2019). $\mathrm{CEPE}-\mathrm{HH}$ is designed to assess the implications of environmental and energy regulation in particular on the consumption and welfare of different Swiss households. Using data from the household budget survey HABE, CEPE-HH calibrates more than 9000 households with respect to their income and expenditure patterns. The general equilibrium nature of the model makes it possible to establish impacts of energy and climate policy on both income and consumer prices that households and producers face. By distinguishing a large number of households of which several socio-economic properties (e.g., house ownership, size of household, age) are known, it is also possible to assess to what extent energy and carbon policy affects some household types more than others.

${ }^{6}$ This assumes that no relevant distortions to the savings decision exist in the economy. 
Table 4 Key features of models participating in the Swiss Energy Modeling Platform

\begin{tabular}{llll}
\hline Name & Type & Regions & Optimization framework \\
\hline STEM & Energy systems model & Switzerland & Cost minimization for the supply of exogenous amounts of energy services \\
CEPE-HH & General equilibrium & Switzerland & Per-period market equilibrium with constant real saving \\
CITE & General equilibrium & Switzerland & Maximization of intertemporal welfare \\
CEPE-316 & General equilibrium & Global & Per-period market equilibrium with constant savings rate \\
GEMINI-E3 & General equilibrium & Global & Per-period market equilibrium model with constant savings rate \\
\hline
\end{tabular}

In order to track energy demand and emissions, the model includes the fossil fuels coal and natural gas, and the mineral oil products motor fuels, heating fuels, and other mineral oil products. Electricity is generated by the four technologies: hydropower, nuclear power (until 2034), power from fossil fuels, and power from renewable energy sources. Electricity supply of the technologies is determined by supply curves with calibrated price elasticities of supply.

The energy demand of households and production sectors of the economy is represented as a subnest of the nested CES utility and production functions. The substitutability of electricity and fossil fuels within that nest increases over time, the two being complements (elasticity of substitution of $0.51>1$ ) before 2020 and ending up as weak substitutes (elasticity of substitution of $1.53>1$ ) by 2050. Demand for motor fuels and other mineral oil fuels substitutes at a constant elasticity of substitution of 0.75 .

Energy demand per real quantity of output of production sectors and consumption utility function decreases over time. The model results are calibrated to the BAU projections by iteratively adjusting the input share parameters of energy demand in the CES functions.

\subsection{CEPE-316}

The CEPE-316 is a recursive-dynamic, multi-country model with 3 regions and 16 sectors. The three regions are Switzerland, the EU, and the rest of the world (ROW). It is based on the GTAP Power dataset 9.1, which contains detailed information on energy sectors and emissions for the year 2011 (Peters, 2016). The model assumes myopic foresight. Capital stock in the next period is calculated using the actual investments and the depreciated capital at the end of the actual period. The sectoral differentiation is geared to the energy questions. The energy sectors are oil, gas, electricity generation (split into peak- or base-load generation from nuclear, coal, gas, wind, hydropower, oil, other energy, and solar), and electricity distribution. The other sectors are transport and the primary, secondary, and tertiary (minus transport) sectors. The transport sector is modeled as most other sectors in the model and does not contain detailed information on transport technologies used. Transportation demand is assumed to grow with the steady-state growth rate without taking into account the move from fossil fuels to electric driven cars. The model allows for exogenous technological change, capacity limits on electricity generation, and inclusions of new generation technologies. One advantage of the model is the multi-regional character, which allows for a more realistic implementation of different emission trading systems, regional endogenous or exogenous energy, or $\mathrm{CO}_{2}$ taxes compared to a single-country model. Furthermore, the consideration of time allows to analyze changes during the transition period of a policy. The advantage of the use of the GTAP 9 Power is the detailed representation of the electricity market.

In the scenarios, we assume that Switzerland and the $\mathrm{EU}$ aim at the same relative reduction level and the EU always implements the EU ETS. For the rest of the world, no targets are set.

\subsection{CITE}

The CITE (Computable Induced Technical change and Energy) model is a dynamic small open economy model of the Swiss economy with fully endogenous growth (Bretschger et al., 2011). The main feature of CITE is that growth in the different sectors is driven by an expansion in the types of intermediate goods (machines), in accordance with the seminal contribution of Romer (1990). Investments in physical capital and knowledge extend the number of capital varieties, which fosters factor productivity. This makes the model suitable for understanding and evaluating the growth and macro-economic impacts of alternative policies.

The CITE model represents different sectors of the economy including 10 non-energy sectors and the electricity sector. Transport is modeled as a non-energy sector without technological detail. Generation technologies are divided in three categories: intermittent technologies including wind and solar, nuclear power (available until 2034), and constant electricity supply technologies including hydropower, conventional thermal plants, electricity from waste, and biomass (Bretschger and Lin, 2017). The trade-offs between and within groups are modeled with CES production functions.

In CITE, a representative consumer allocates income between consumption and investments to maximize its intertemporal utility under perfect foresight. In every 
period, the total consumption is given by a CES function of energy and the composite of non-energy goods. Energy consumption consists of electricity and of fossil fuels in a CES fashion.

Households provide capital and labor to firms which use these factors to produce commodities. These commodities are either sold to domestic industries as intermediate input and consumers or exported to other regions.

\subsection{GEMINI-E3}

GEMINI-E3 (General Equilibrium Model of InternationalNational Interactions between Economy, Energy, and the Environment) is a multi-country, multi-sector, recursive computable general equilibrium model (Bernard and Vielle, 2008). The model is specifically designed for the analysis of climate change and energy policies. It is a global model built using the GTAP database and the Swiss input-output table.

The standard model is based on the assumption of total flexibility in all markets, both the macroeconomic markets such as the capital and the exchange markets (with the associated prices being the real rate of interest and the real exchange rate, which are endogenous), and the microeconomic or sector markets (goods, factors of production). For each sector, the model computes the demand for its production on the basis of household consumption, government consumption, exports, investment, and intermediate uses. Total demand is then divided between domestic production and imports, using the Armington assumption. Under this convention, a domestic product is distinguished from an imported product of the same industry. Production technologies are described using nested constant elasticity of substitution (CES) functions.

GEMINI-E3 is recursive dynamic, with backwardlooking (adaptative) expectations. In this model, time periods are linked through endogenous real interest rates that equate savings and investment. Capital is not mobile across regions. National and regional models are linked by endogenous real exchange rates resulting from constraints on foreign trade deficits or surpluses.

The version of GEMINI-E3 used under the Swiss Energy Modeling Platform includes a specific representation of the road transport sector where several types of vehicles are detailed according to the fuel used. Indeed, the model distinguishes electric vehicles, which are mainly dedicated to short or medium distance, and two other types using the same motorization (i.e., internal combustion), one using petroleum products, and the other biofuels. Electricity generation is represented by a nested CES function that includes the new capacities installed in renewable technologies, in addition to fossil fuels and nuclear and hydropower plants.

GEMINI-E3 assumes no climate policy outside of Switzerland in all the scenarios.

\subsection{STEM}

The Swiss TIMES energy system model (STEM) is a bottom-up, technology-rich model of the Swiss energy system (Kannan and Turton, 2014). The energy system of Switzerland is represented from resource supply to energy service demands (ESDs) by five end-use sectors (which are services, transport, residential, industry, and agriculture). The model is calibrated to 2015 Swiss energy statistics (BFE, 2016). The model has a high level of technology detail, a long time horizon (2010-2050+ ${ }^{7}$, and an hourly representation of weekdays and weekends in three seasons. The model is used to identify the least-cost combination of technologies and fuels to meet exogenously given ESDs while fulfilling other technical, environmental, and policy constraints. The representation of the entire energy system enables STEM to determine the lowest-cost configuration of the energy system accounting for crosssectoral interactions and competition for the allocation of energy carriers (for instance, the allocation of biomass to electricity, heat, or transport).

STEM is a single-region model of Switzerland with an implicit region of rest of the world, from which energy commodities are imported at given price. Since, electricity import and export are subjected to interconnectors between Switzerland and its four neighboring countries, the interconnectors are explicitly modeled in STEM.

Although STEM covers the whole energy system in detail, there is no representation of the broader economic sector and implications of policies for the non-energy sectors, such as tax recycling and interaction effects, cannot be assessed. In an energy system model like STEM, applying sectoral carbon caps generally increases the energy system cost of reaching a given level of emissions because the flexibility to abate emissions where it is cheapest is reduced. On the other hand, the model includes neither distortionary pre-existing taxation outside the energy sector nor interdependencies in the production chains between non-energy sectors, both of which are reasons economy-wide models may find sectoral caps to have some benefit. In light of this, the STEM modelers abstained from modeling any scenarios with different taxes in the ETS and non-ETS sectors.

\section{Business-as-usual scenario: effect of current policies on energy, emissions, and carbon price} We consider in the BAU scenario a potential annual economic growth rate of $1.28 \%$ per annum following the projections of the State Secretariat for Economic Affairs (SECO) and a levy on heating fuels from the $\mathrm{CO}_{2}$ ordinance (Swiss Federal Council, 2013b) that reaches a level of $\mathrm{CHF} 120 / \mathrm{tCO}_{2}$ in 2020 . Table 5 summarizes the

\footnotetext{
${ }^{7}$ Results up to 2100 can be generated. Due to the considerable uncertainties about long-run developments and end-of-horizon effects, results beyond 2050 are usually not communicated.
} 
Table 5 BAU scenario: harmonizing assumptions

\begin{tabular}{|c|c|c|c|c|c|}
\hline & 2010 & 2020 & 2035 & 2050 & Reference \\
\hline Potential GDP (rel. to 2010) & 1 & 1.18 & 1.43 & 1.66 & SECO $2015^{\mathrm{a}}$ \\
\hline Total energy use (rel. to 2010) ${ }^{\mathrm{b}}$ & 1 & 0.94 & 0.84 & 0.78 & BAU scenario, Prognos (2012) \\
\hline Electricity use (rel. to 2010) ${ }^{\mathrm{b}}$ & 1 & 1.05 & 1.10 & 1.18 & BAU scenario, Prognos (2012) \\
\hline $\mathrm{CO}_{2}$ tax heating fuels $\left(\mathrm{CHF} / \mathrm{tCO}_{2}\right)$ & 36 & 120 & 120 & 120 & $\mathrm{CO}_{2}$ Levy (Swiss Federal Council, 2013b) \\
\hline $\mathrm{CO}_{2}$ tax transport fuels $\left(\mathrm{CHF} / \mathrm{tCO}_{2}\right)^{\mathrm{c}}$ & 0 & 0 & 0 & 0 & $\mathrm{CO}_{2}$ Levy (Swiss Federal Council, 2013b) \\
\hline Cap on emissions from ETS sectors (relative to 2013) & & 0.88 & 0.68 & 0.52 & EU ETS yearly reduction \\
\hline
\end{tabular}

${ }^{a}$ Data provided by the Swiss State Secretariat for Economics Affairs (SECO)

${ }^{b}$ Assumption used in CEPE-HH, CEPE-316, and CITE. GEMINI-E3 uses its energy efficiency assumptions. STEM has exogenously driven assumptions on energy service uses (e.g., heating/lighting/air conditioning) based on Prognos (2012) and finds the least costly supply option

CThe STEM model includes in the BAU scenario the existing mineral oil tax and climate levy for heating fuels

${ }^{\mathrm{d}}$ The cap is computed using a yearly reduction factor of $1.74 \%$ used in the EU ETS until 2020

assumptions of the BAU scenario. These variables are used for the calibration of the model in the following way.

CGE models use projected GDP growth to scale the availability of fundamental production factors (labor, capital, and resources if applicable $)^{8}$. Use of energy and electricity may be calibrated differently by different models. Some models used the use-per-GDP ratio to implement energy efficiency improvements in the BAU scenario, and others calibrated to absolute projected use of energy and electricity by an iterative procedure. All CGE models further modified energy use in the BAU by implementing the ETS cap, which decreases fossil fuel demand in the ETS sectors. Finally, the $\mathrm{CO}_{2}$ taxes and the cap on the emissions from the ETS sectors are inputs used directly in the BAU calibration by the different models. The resulting $\mathrm{CO}_{2}$ tax in the coming sections is a weighted average by emissions of the carbon taxes in the different sectors.

The energy system model STEM uses its own BAU projections (e.g., GDP and population) and infers energy service demands from them ${ }^{9}$. STEM's projections have not been synchronized with SEMP's, but they are reasonably similar and derive from similar sources. And while CGE models commonly represents energy efficiency improvements from technological progress by parametrically changing aggregate energy intensity of sectors, STEM has its own detailed representation of innovations on the level of single technologies.

Figure 1 presents the main consequences of such policies on the energy system, the $\mathrm{CO}_{2}$ emissions, and the economy-wide carbon tax. With current climate policies, as modeled in the BAU scenario, most of the SEMP models find that total final energy use reduces $14-20 \%$ in 2050 compared to today's levels (see Fig. 1a). This decrease can

\footnotetext{
${ }^{8}$ Under steady state assumptions (i.e., inputs and outputs of all sectors, trade, and government spending grow at the same rate; prices on the global market stay constant relative to the Swiss franc), this would result in the same scaling of GDP. Due to assumptions about energy efficiency improvements, fuel price changes on the global markets, and a binding ETS cap, the models' GDP figures will deviate from the projections somewhat.

${ }^{9} \mathrm{~A}$ mapping of the socioeconomic drivers and energy system demands is documented in Section 8.2 in Kannan and Turton (2014).
}

be observed in the demand of all economic activities, but its particularly strong in the transport and residential sectors. Most of the CGE models assume exogenous reductions of transport fuel use per GDP over time reflecting changes in technology choices and regulation. GEMINIE3 and the energy systems model STEM more explicitly model a shift from the conventional internal combustion engine (ICE) cars toward energy efficient hybrid or electric cars. STEM also explicitly model the replacement of the existing oil-based heating systems by heat pumps (due to high $\mathrm{CO}_{2}$ tax).

With regard to the electricity sector, the BAU scenario results in an increase of electricity use across models of $10-28 \%$ in 2050 compared to 2010 (see Fig. 1b).

When implementing current policies in the different models, the economy-wide carbon price reaches a level of 56-106 CHF2010/tCO $\mathrm{tC}_{2}$ in 2050 for all models. The very similar carbon prices lead to similar reductions in $\mathrm{CO}_{2}$ emissions, reaching levels of 21.6-32.7 $\mathrm{MtCO}_{2}$, which is significantly higher than the goals of 1.0 and $1.5 \mathrm{tCO}_{2}$ per capita (8 and $12.9 \mathrm{MtCO}_{2}$ ).

\section{Results for uniform carbon taxes}

Emissions in the BAU scenario in the different models are in the range of 21.6-32.7 $\mathrm{MtCO}_{2}$. Therefore, reaching the targets of 1.5 or 1.0 tonne $\mathrm{CO}_{2}$ per capita in 2050, corresponding to 12.1 and $8.1 \mathrm{MtCO}_{2}$, requires policies additional to those currently in place. In our analysis, the principal policy that is assumed to reduce emissions from BAU levels to the scenario-specific targets is a carbon price. In this section, we analyze the case in which a unique carbon price is applied to the whole economy.

\subsection{Energy use}

All models find that realizing the climate targets requires a reduction in final energy use compared to the BAU. For 2050 , the reduction in final energy is $5-39 \%$ and $17-46 \%$ for reaching the targets in the 1.5_uni and 1.0_uni scenarios, respectively (see Fig. 2a, c). These reductions are 


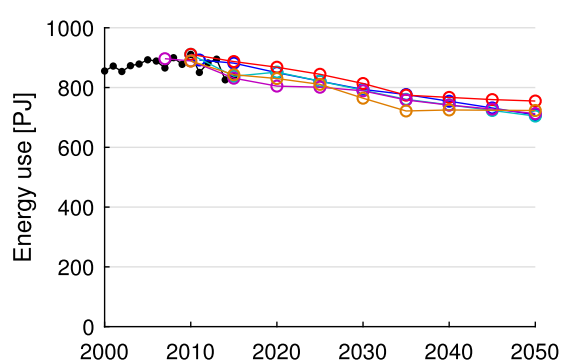

(a)

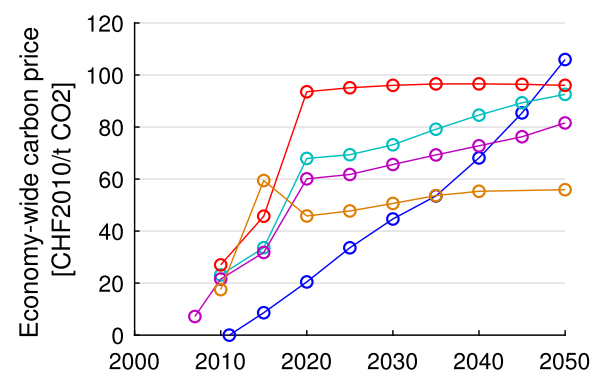

(c)

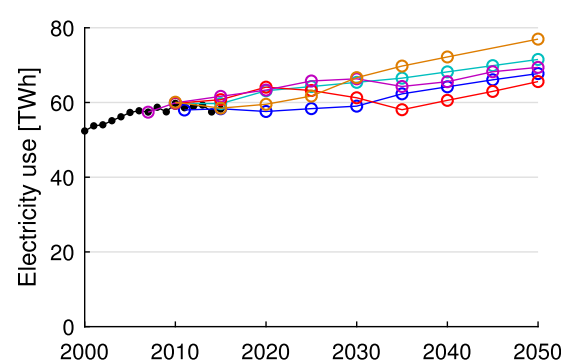

(b)

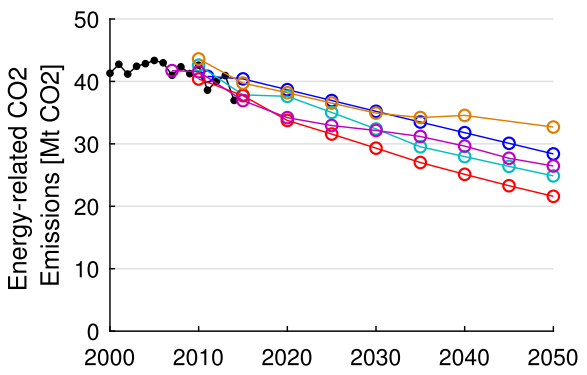

(d)

Fig. 1 BAU scenario. a Final energy use. b Electricity use. c Economy-wide carbon price. d Carbon emissions

driven by less fossil fuels used in all sectors and the use of more efficiency appliances and buildings (modeled specifically in STEM and with substitution between energy use and capital in the CGE models).

One of the specific targets of the Swiss Energy Strategy 2050 is the reduction of per capita energy use in 2035 by $-43 \%$ compared to 2000 levels ${ }^{10}$. We find that the target for total energy use is consistent with the findings of all SEMP models, which show a reduction of per capita energy use by 2035 (from 2000 levels) of 37-49\% and 44$52 \%$ in the 1.5_uni and 1.0_uni scenarios, respectively. This reduction in per capita levels implies a reduction in national energy use of $15-30 \%$ and $23-39 \%$ in the 1.5 uni and 1.0_uni, respectively.

Concerning the electricity sector, in the scenarios with emission targets, all models continue to have increasing electricity use compared to 2010 levels. Compared to the $\mathrm{BAU}$, one group of models finds that electricity use in 2050 for the $1.5 \mathrm{tCO}_{2}$ p.c. target decreases by $2-8 \%$ (CEPE316, CEPE-HH, and STEM). The two remaining models show a 10\% larger 2050 electricity use (GEMINI-E3 and CITE). The latter models allow for a larger increase in electricity use through the availability of carbon capture and storage (CCS) (GEMINI-E3) or a slight increase in solar production and electricity imports (CITE).

\footnotetext{
${ }^{10}$ See, e.g., https://www.bfe.admin.ch/bfe/en/home/policy/energy-strategy2050/documentation.html (last accessed 12 August 2019).
}

The target in the Swiss Energy Strategy regarding electricity use is to reduce it in per capita levels by $-13 \%$ in 2035 (relative to 2000). The use of electricity per capita found by three SEMP models (CEPE-HH, GEMINI-E3, STEM) is higher than the target defined by the Swiss Energy Strategy, with changes in 2035 of -4 to $-8 \%$ ( $-20 \%$ for CEPE-316 and CITE) and -5 to $-7 \%$ compared to 2000 for the 1.5_uni and 1.0_uni scenarios, respectively. By 2050, all models find that per capita electricity use should change by -15 to $2 \%$ and -11 to $9 \%$ compared to 2000 levels. The model results reflect the fact that in Switzerland, electricity is an attractive replacement of fossil-based energy sources, since electricity generation there has a low $\mathrm{CO}_{2}$ emission intensity.

The distribution of the reductions (relative to BAU) in energy use and emissions among the different economic activities is shown in Fig. 3 for the 1.5_uni scenario ${ }^{11}$. Concerning the energy use, in CEPE-316, CEPE-HH, and STEM, the reductions occur across the industrial, residential, and transport sectors, while in the CITE and GEMINI-E3 models, the reductions occur mainly in the transport and industrial sectors. In the CITE model, the slight increase in the energy use in the residential sector is driven by higher electricity use. In the STEM model, the high reduction in the residential sector is driven by

\footnotetext{
${ }^{11}$ The distribution of the use reductions in the 1.0_uni scenario is similar to that in the 1.5_uni and is not presented here.
} 


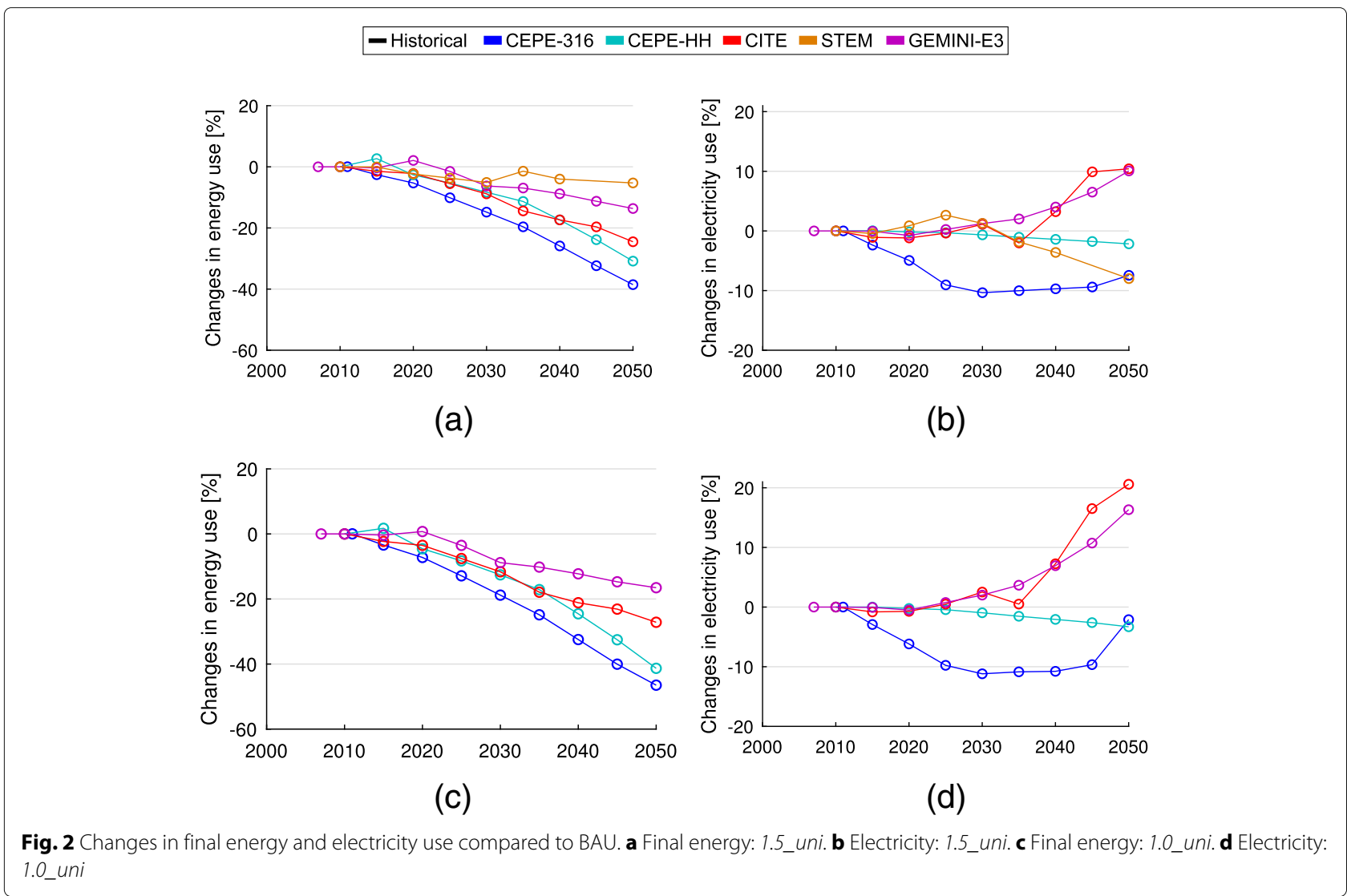

two factors. First, a high $\mathrm{CO}_{2}$ tax on heating fuels drives the replacement of fossil fuel-based heating systems electric heat pumps in the residential sector (and increases the electricity use). Secondly, STEM only represents building energy conservation measures (e.g., insulation) for the residential sector, which is why mitigation options in the residential sector are larger than in the other sectors.

Regarding the reduction in emissions, the decrease in emissions in the electricity sector plays a moderate role, except for the STEM model (and to a smaller extent GEMINI-E3), where gas power plants play an important role in BAU electricity generation and are used less (or in combination with CCS in the case of GEMINI-E3) when the climate policy is imposed. In the other models, around half of the reduction in emissions takes place in the transport sector.

\subsection{Electricity generation}

The second objective of the Swiss Energy Strategy is the large deployment of renewable-based technologies for the production of electricity. Figure 4 shows the electricity generation (without trade) resulting from all SEMP models in the BAU and the 1.5_uni scenarios.

All models assume that the existing nuclear power plants are phased out step-wise until reaching a total phase out by $2035^{12}$. In the BAU scenario, with the current policies, all models find that hydropower, gas generation, and solar PV are the most attractive technologies. The main change when imposing the longterm climate targets is a decrease in the use of gas and a larger use of renewables. All models show that to achieve the long term emission targets, by 2035 and 2050 , after nuclear power is phased out, $20-40 \%$ of the electricity production is coming from "new" renewables (not including hydropower). The two extreme cases are CEPE-316, where electricity is generated using biomass and hydropower, but there is a significant amount of electricity imports from neighboring countries reaching approximately $40 \%$ of use, and the STEM model that assumes the highest solar PV potentials and includes geothermal as one of the technology options. The differences in the use of solar PV come mainly from the differences in the assumptions about maximum potential shown in Table 6. GEMINIE3 includes gas generation combined with CCS, which helps realizing a higher level of low-carbon electricity generation.

\footnotetext{
${ }^{12}$ This is a simplifying assumption done in the SEMP model to represent the decision of the Federal Council of operating the nuclear power plants as long as they are safe. In the STEM model, some nuclear generation is seen in 2035 because the value is the annual average of the period 2033-2037.
} 


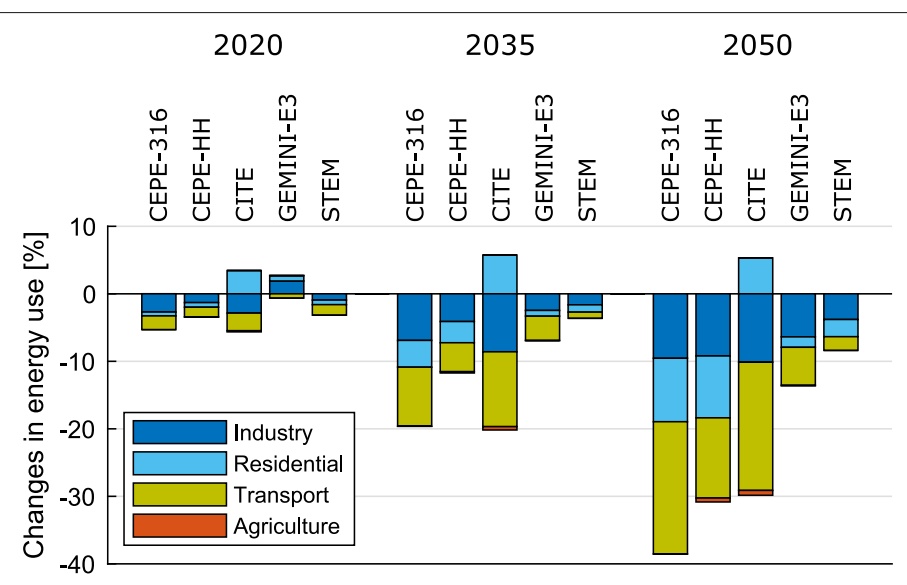

(a)

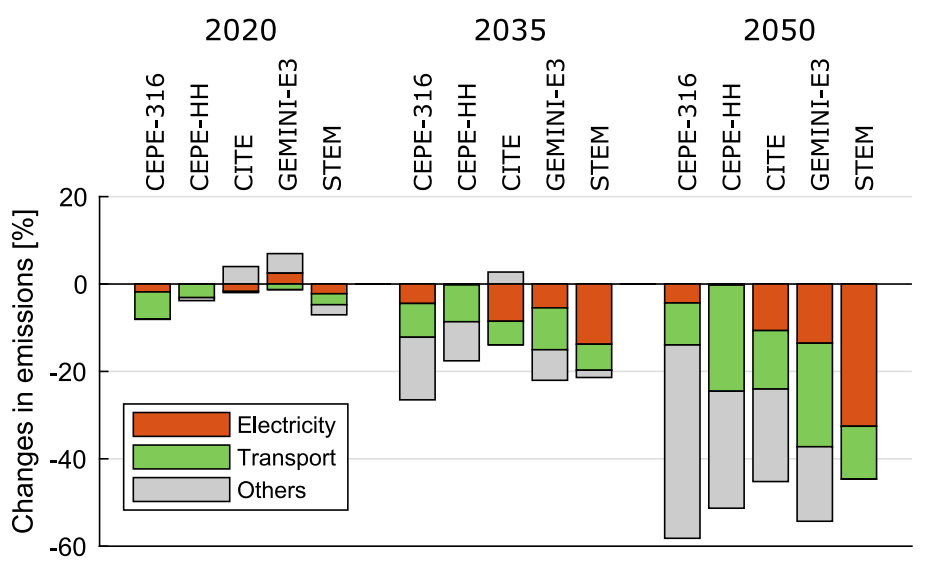

(b)

Fig. 3 Changes in energy use (above) and emissions (below) by economic activity in the 1.5_uni scenario compared to BAU. a Changes in energy use. The category industry includes the service sector. $\mathbf{b}$ Changes in emissions

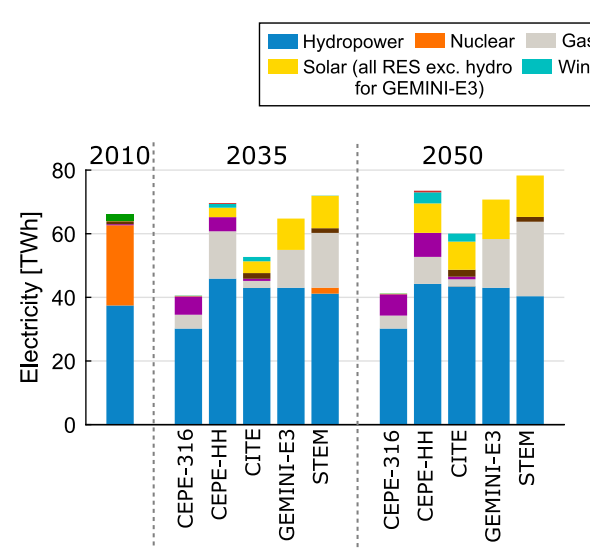

(a)

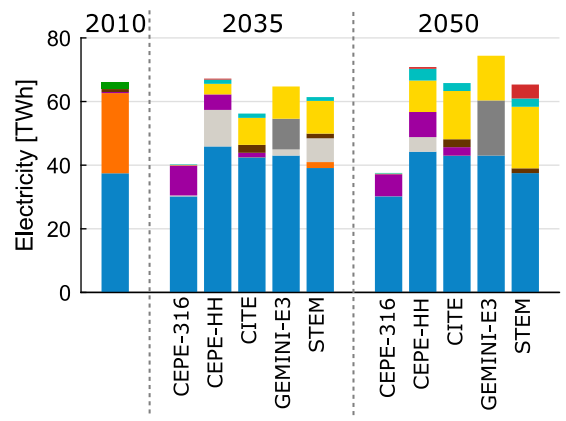

(b)

Fig. 4 Electricity generation. Note that the GEMINI-E3 model has one renewable technology that aggregates all renewables other than hydro; hence, the yellow color represents all renewables (excluding hydro). a BAU. b 1.5_uni 
Table 6 Renewable potentials

\begin{tabular}{|c|c|c|c|}
\hline \multirow[t]{2}{*}{ Model } & \multirow[b]{2}{*}{ Solar } & \multicolumn{2}{|c|}{ Potential (TWh) } \\
\hline & & Wind & Geothermal \\
\hline CEPE-316 & 2.6 & 0.8 & - \\
\hline CEPE-HH & $\begin{array}{l}\text { Renewable power } \\
\text { supply in CEPE-HH is } \\
\text { price dependent but } \\
\text { not limited }\end{array}$ & & - \\
\hline CITE & 15 & 2.5 & - \\
\hline GEMINI-E3 & 14 & 4.2 & - \\
\hline STEM $^{\mathrm{a}}$ & 19 & 4.2 & 4.4 \\
\hline
\end{tabular}

aSTEM includes resource potentials for all energy resources (wood, bio-waste, etc.)

A strength of technology rich models, such as STEM, is their long time horizon and hourly temporal resolution. Figure 5 shows the hourly electricity supply and use on average summer and winter weekdays in 2050 for the 1.5_uni scenario. By 2050, the difference in the use of electricity in the peak between summer and winter reduces compared to 2015. This is partly because of increasing air-conditioning uses in summer and the uptake of energy conservation measures in the buildings sector, which reduces winter electricity use. The existing hydropower fleet continues their production, which requires refurbishment of a part of the existing hydropower plants, as well as new investments in small hydropower plants. Today's base-load nuclear plants are fully replaced with new renewable and combined heat and power (CHP) plants by 2050; electricity supply from the latter is increasing in winter. CHP plants produce both high- and low-temperature heat for industrial sectors and contribute to an overall more efficient use of natural gas and hence a decline in $\mathrm{CO}_{2}$ emissions. Excessive generation from solar PV in summer is exported, and some electricity is imported in winter to achieve a balanced annual electricity trade. Resulting from STEM assumptions on international electricity prices, during winter night time, imported electricity is used to meet the domestic electricity uses, while during daytime and evening hours, electricity generation from dam hydro is exported. As long as the flexibility of interconnectors prevails, the Swiss energy system can cope with the energy transition in terms of nuclear phase out, deployment of new renewables, and climate mitigation. However, there is large uncertainty in the market for exporting excessive generation as well as for sources of imports.

\subsection{Carbon prices}

The economy-wide carbon tax needed for the two climate scenarios is shown in Fig. $6^{13}$. In the CGE models, the tax

\footnotetext{
13 The results do not include the carbon taxes from the STEM model because the carbon taxes resulting from the model correspond to the marginal cost of
}

needed to achieve the $1.5 \mathrm{tCO}_{2}$ per capita target ranges from 91 to $324 \mathrm{CHF}_{2010} / \mathrm{tCO}_{2}$ in 2035, depending on the model, and from 529 to $652 \mathrm{CHF}_{2010} / \mathrm{tCO}_{2}$ in 2050. In the 1.0_uni scenario, the resulting carbon prices lie within the ranges $116-376 \mathrm{CHF}_{2010} / \mathrm{tCO}_{2}$ in 2035 and $970-1089$ $\mathrm{CHF}_{2010} / \mathrm{tCO}_{2}$ in 2050 . This corresponds to an increase compared to the 1.5_uni case of 16-44\% in 2035 and 65$84 \%$ in 2050 . All models have very similar carbon taxes, reflecting the pressure on the economy of achieving the two climate targets.

\section{Results for differentiated carbon taxes}

Real-world policy proposals hardly ever consider an economy-wide, uniform carbon price. They usually at least include a separate target (an annually decreasing emissions cap) for emissions by energy-intensive sectors included in the ETS. This is in keeping in line with EU policies and allows for future harmonization of the EU and Swiss climate policy. Also, Swiss policy proposals often differentiate carbon tax rates between fuels; the $\mathrm{CO}_{2}$ tax on transport fuels is lower than the tax on other fuels. Such deviations from a uniform carbon tax may be motivated by a so-called tax interaction effect. Preexisting high taxes on transport fuels create a situation where carbon taxation induces emission reductions in a sector where fuel use is already considerably lower than it would be in a world without taxes. As the low-cost abatement options are already implemented, additional abatement efforts in transportation are therefore more expensive than elsewhere in the economy. In the following, the SEMP modeling results are scrutinized to determine whether differentiating carbon taxes on transport fuels from heating fuel tax levels may be a beneficial strategy for efficiently reaching the policy targets in 2050.

The cumulative discounted 2010-2050 welfare losses ${ }^{14}$ for the two climate scenarios compared to the BAU case are shown in Fig. $7^{15}$. This allows for a comparison of different policy choices for reaching given emission targets from the present perspective. For scenarios 1.5_uni and 1.0_uni, which employ an economy-wide uniform carbon tax to reach their respective targets, the discounted net present value of welfare losses amounts to $0.15-1.7 \%$ and $0.24-2.6 \%$. The results suggest that the ambitious climate policy targets can be achieved within the range of expected benefits from keeping the global climate externality in check (see, e.g., Stern (2007)).

carbon, i.e., the dual value of the carbon constraint, which exceeds 1000 $\mathrm{CHF} / \mathrm{t}$ from 2040 and beyond.

${ }^{14}$ Cumulative discounted values are calculated with a $5 \%$ discount rate.

${ }^{15}$ The energy systems model STEM does not include a consumer welfare measure. It reports cumulative "energy system" cost for the period 2015-2050 to achieve the climate policy target, which implies an additional costs (relative to the BAU scenario) of about CHF 165 billion corresponding to about $0.6 \%$ of the average annual GDP. These additional costs mainly reflect capital expenditure for moving toward a more capital-intensive system that reduces costs on fuels and taxes. 

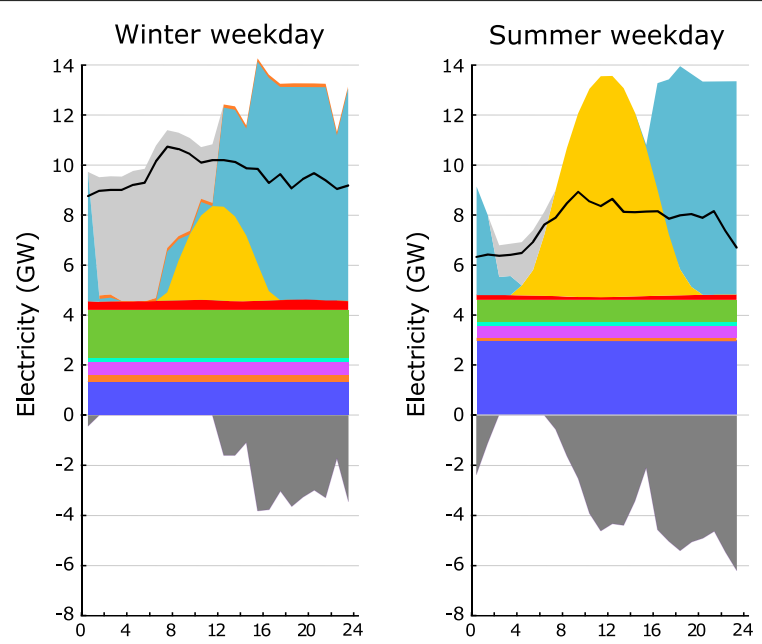

\begin{tabular}{|l|}
\hline - Demand \\
Hydro (river) \\
Hydro (dam) \\
Solar PV \\
$\square$ Wind \\
CHP Distributed \\
Waste/biomass \\
Geothermal \\
CHP Gas \\
Imports \\
Exports
\end{tabular}

Fig. 5 Electricity supply and use from STEM on typical summer and winter weekdays

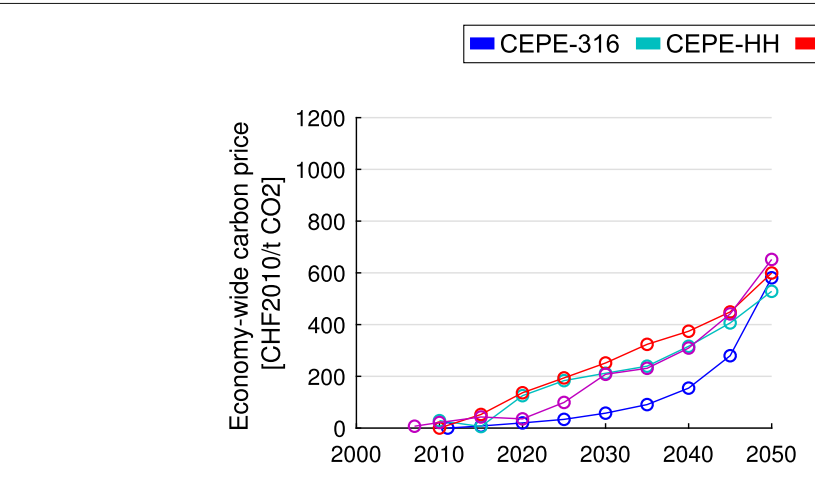

(a)

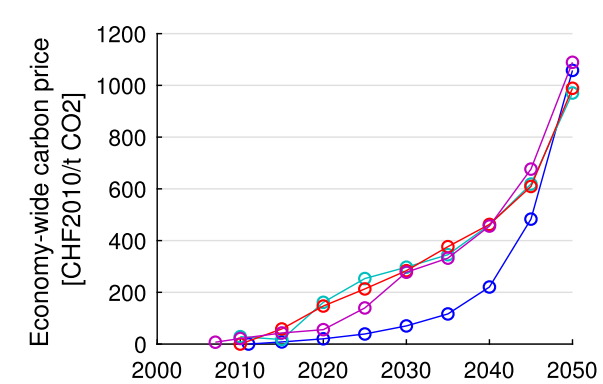

(b)

Fig. 6 Economy-wide carbon tax in the a 1.5_uni and b 1.0_uni scenarios

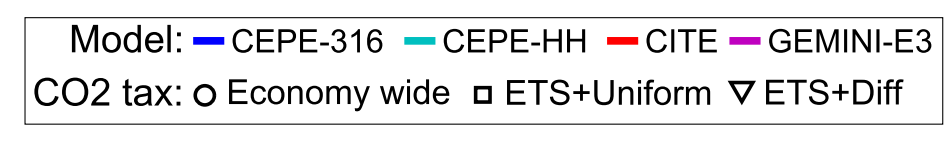

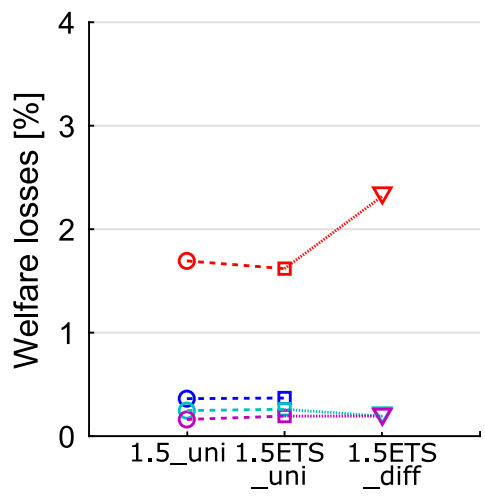

(a)

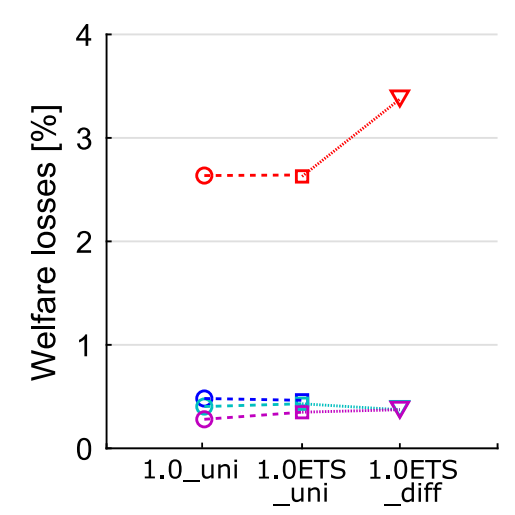

(b)

Fig. 7 Cumulative welfare losses. a 1.5 tpc per target. b 1.0 tpc per target 
$-\mathrm{CEPE}-316-\mathrm{CEPE}-\mathrm{HH}=\mathrm{CITE}-\mathrm{GEMINI}-\mathrm{E} 3$ - - - CO2 tax non-ETS sectors ………"... CO2 tax ETS sectors


Fig. 8 ETS permit prices and carbon taxes for the scenarios 1.5_uni/1.0_uni and 1.5ETS_uni/1.0ETS_uni according to different models

In an economy with perfectly competitive markets and without initial distortions (e.g., pre-existing taxes), the uniform carbon tax is known to produce the most efficient abatement patterns for reaching an emission reduction target. Yet, Fig. 7 shows that the introduction of a separate cap on emissions from ETS sectors increases welfare in some models, which indicates that the preexisting taxes in interaction with the uniform carbon tax produced too much or too little abatement in the ETS sectors compared to the rest of the economy. The fact that the ETS permit price and thus abatement efforts by ETS sectors in scenarios 1.5ETS_uni and 1.0ETS_uni are lower than under the uniform carbon tax in scenarios 1.5_uni and 1.0_uni (see Fig. 8) suggests that according to CEPE-316 and GEMINI-E3, there was an inefficiently high abatement by ETS sectors in the latter scenarios.

Differentiating carbon prices outside the ETS for heating and transport fuels in scenarios 1.5ETS_diff and 1.0ETS_diff has different effects in different models. CITE and GEMINI-E3 both find higher welfare losses for such tax differentiation whereas CEPE-HH finds this scenario the most efficient in terms of discounted welfare ${ }^{16}$. Considering welfare by single model periods reveals a more nuanced picture (see Fig. 9). Both CEPE-HH and GEMINI-E3 find taxing non-ETS emissions with differentiated tax rates to be preferable over taxing them uniformly in the year 2025 (compare 1.5ETS_uni/1.0ETS_uni to 1.5ETS_diff/1.0ETS_diff). This preference order of

\footnotetext{
${ }^{16}$ Indeed, the scenarios 1.0ETS_diff and 1.5ETS_diff have been designed with the results of Landis et al. (2018) in mind, where the model CEPE-HH with lower household resolution had been applied to find that tax differentiation can be welfare maximizing. To a certain extent, this result has been found to hold even if the pre-existing mineral oil tax could be justified by the negative externalities of transport (viz. accidents, non-climate related pollution, and congestion).
}

policies persists even until 2030 for the 1.5_uni target according to GEMINI-E3's results and until 2040 (2045) for the 1.0_uni (1.5_uni) target according to CEPE-HH.

The different degrees of preference for tax differentiation across models may be explained by the detail with which pre-existing taxes are modeled. When we compare the different models' assumptions about pre-existing taxes on the different fuel types, we find that both CEPE-HH and GEMINI-E3 have large differentials between heating fuels and transport fuels ${ }^{17}$.

CEPE-HH and GEMINI-E3 both implement this preexisting tax as a fix tax on demand of physical units of fossil fuels and thus keep the payments constant even in scenarios where market prices for fossil fuels are depressed by reduced demand for them. We observe that the different rankings of tax designs by CEPE-HH and GEMINI-E3 coincide with differences in initial tax rates (expressed in ad valorem terms). It is important to note that the policy ranking of the different models only differs for the less ambitious targets in the earlier years of climate policy. According to all models, the argument for partly excluding transport fuels from the $\mathrm{CO}_{2}$ tax becomes weaker as this tax rises and absolute difference between the consumer prices for heating and transport fuels becomes bigger due to the tax differentiation.

The changes in relative carbon prices on motor and heating fuels cause different abatement patterns (compare upper to lower panel in Fig. 10). The energyrelated emissions in transport decrease less if transport fuels benefit from a reduced carbon tax compared to heating fuels. Thus, realizing the emission targets

\footnotetext{
${ }^{17}$ The assumed average tax on transport fuels is $101 \%$ and $80 \%$ for CEPE-HH and GEMINI-E3, respectively, while the tax on heating fuels is $0-0.4 \%$ in GEMINI-E3 and $0.4-7.7 \%$ in CEPE-HH.
} 


\section{Model: - CEPE-316 - CEPE-HH - CITE - GEMINI-E3 CO2 tax: o Economy wide $\square$ ETS+Uniform $\nabla E T S+D i f f$}

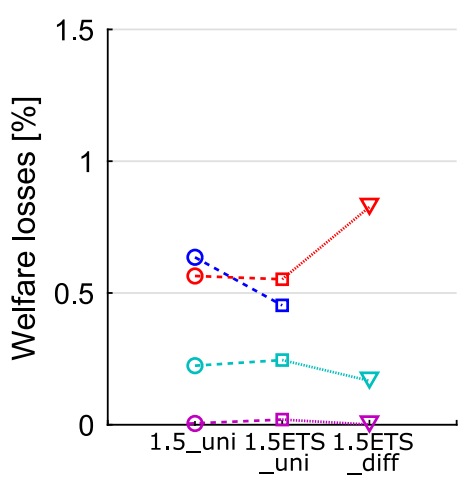

(a)

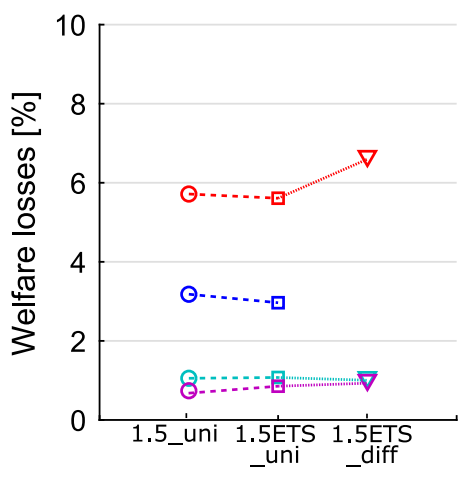

(c)

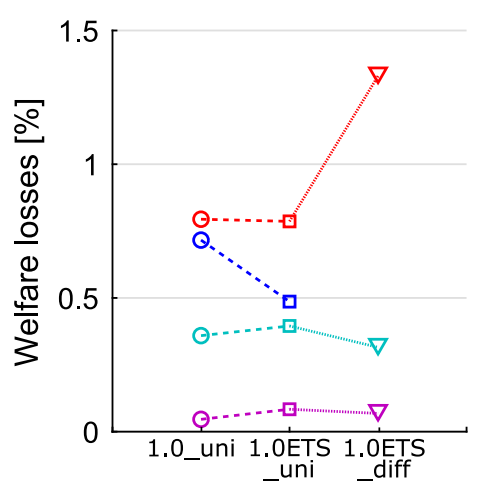

(b)

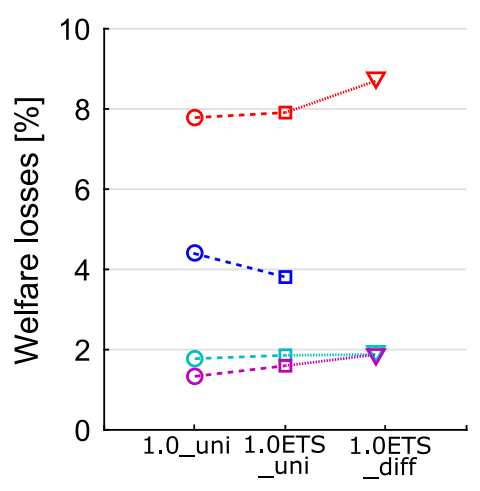

(d)

Fig. 9 Welfare losses in single model periods across different policies according to the various CGE models. a 1.5 tpc scenarios in 2025 . b 1.0 tpc scenarios in 2025. c 1.5 tpc scenarios in 2050. d 1.0 tpc scenarios in 2050

requires additional abatement in other sectors. According to GEMINI-3 and CITE, both electricity generation and the remainder of the economy should compensate the increased emissions in the transport sector. In the $\mathrm{CEPE}-\mathrm{HH}$, electricity generation does not reduce any relevant fraction of emissions and all additional emission reductions have to be made in the remainder of the economy.

\section{Discussion and conclusions}

This paper analyzes the consequences on the Swiss economy and energy system of reaching two carbon reduction targets using alternative climate policy designs. For this analysis, we compare the results from different quantitative models, including four CGE and one energy systems model. We find robust common trends despite the differences in model types and underlying assumptions concerning energy use, electricity use and supply, and carbon taxes.

The paper focuses on two long-term climate targets: 1.5 and 1.0 tonne $\mathrm{CO}_{2}$ per capita in 2050. It pays attention to the needed changes in total and sectoral energy uses, the restructuring of the electricity sector, and the possible economic consequences of achieving such climate goals. Moreover, the paper analyzes how different designs of carbon taxation (with respect to differentiation of tax levels across fuels or sectors) are ranked concerning efficiency by the different models.

We find that the reduction of emissions goes hand in hand with a sizeable reduction in per capita energy use, while per capita electricity use remains more or less constant compared to today's levels, in particular in the long run. Thus, reductions in per capita energy use found by the different SEMP models are consistent with those 


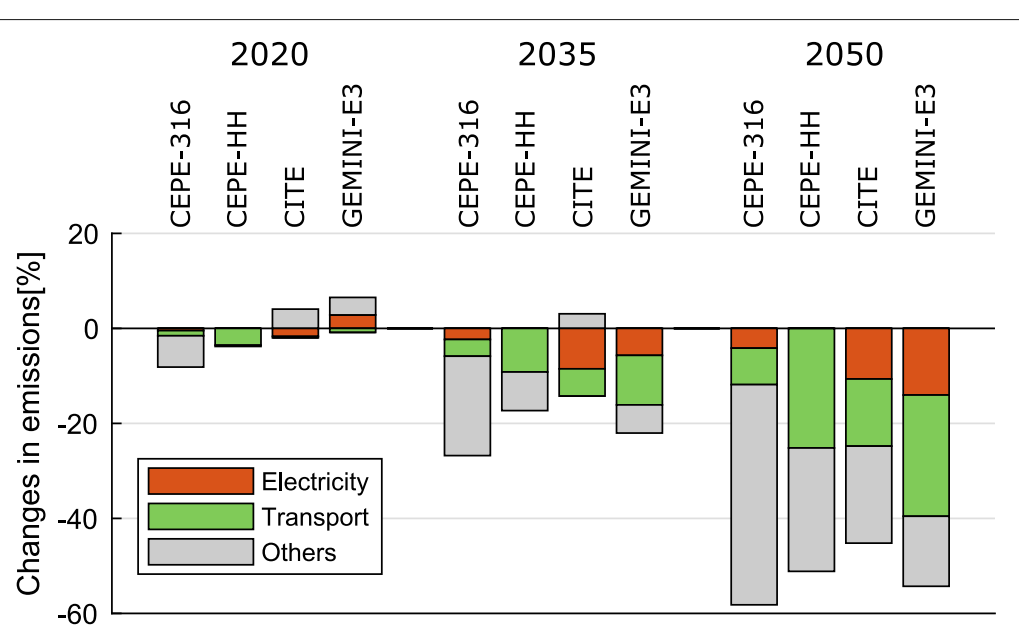

(a)

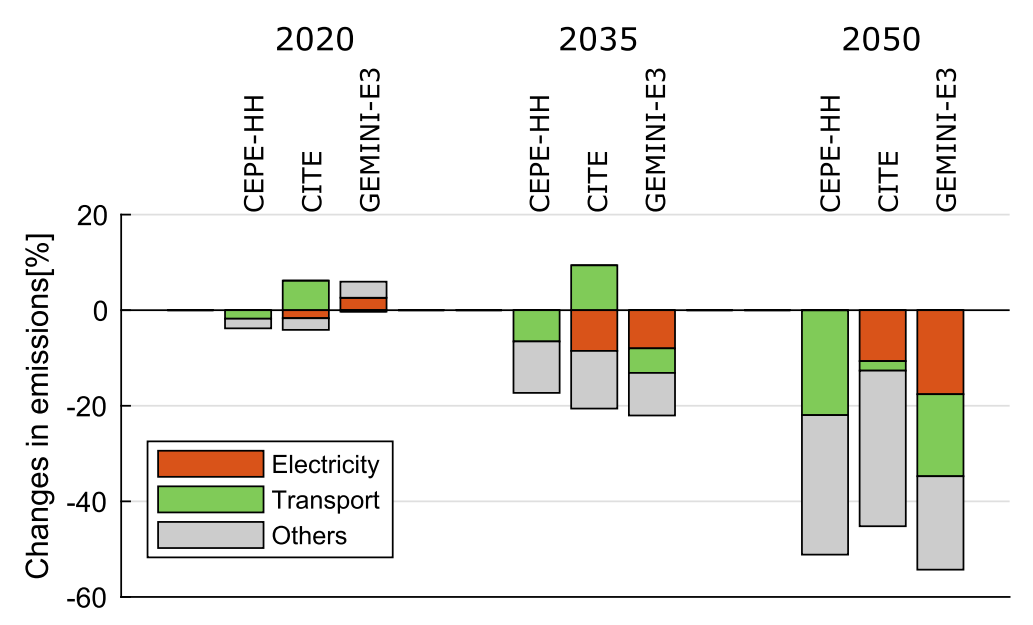

(b)

Fig. 10 Changes in emissions relative to BAU for different years for the scenarios a 1.5ETS_uni and b 1.5ETS_diff by economic activity

currently envisaged by the 2050 Swiss Energy Strategy, while most of the models find that per capita electricity use needs to be reduced less than currently proposed in the Swiss Energy Strategy (in particular, models that assume carbon capture and storage to be viable or that assume the possibility of net imports of electricity find higher levels of electricity use to be efficient). As electricity in Switzerland (today and in the projections of the SEMP models) is produced with very low levels of GHG emissions, it is an attractive form of energy for replacing carbon-intensive fossil fuels (e.g., in the heating sector) when aiming for ambitious climate targets.

While all models find that an increase in electricity use compared to the 2010 level is needed, the electricity supply differs more across the models. All SEMP models find that replacing the phased-out nuclear power requires the deployment of renewable-based electricity options, including hydro, solar, biomass, wind, and to some extent geothermal. The differences across models in the supply of electricity are due to assumptions concerning electricity imports and the availability of CCS. When models assume cheap imports to be available, the levels of domestic electricity supply are lower and come mainly from hydropower and renewables. It has to be noted that the reliance on electricity imports implies risks to the security of supply and might cause carbon leakage from Switzerland to the neighboring countries if the electricity generation there is more carbon intensive. Models do not make the trade-off between security of supply, carbon leakage, and electricity cost, but most of the models impose a high degree of electricity autarky and have the additionally needed power generated from sources such 
as gas turbines and solar PV. Within this group, models that allow for the deployment of CCS find larger levels of electricity supply than models that have to expand costly renewable energy sources such as PV.

We find that current climate policies in Switzerland result in an economy-wide tax in 2050 in the range of 56-108 $\mathrm{CHF} / \mathrm{tCO}_{2}$, which leads to reductions in energyrelated emissions by 2050 in the range of $25-45 \%$ compared to 2010 levels. These abatement levels are less than the targets set by the Swiss government, aiming at reducing emissions in 2050 by around $80 \%$. Thus, we analyze the effect of alternative designs of policies that achieve these targets. The analyzed carbon tax options include (1) an economy-wide tax, (2) different tax rates for ETS and non-ETS sectors, and (3) different carbon taxes for ETS sectors, heating, and transport fuels. Concerning the economy-wide tax scenarios, the CGE models in SEMP find that realizing the 2050 emission targets of $1.5 \mathrm{tCO}_{2}$ p.c. and $1.0 \mathrm{tCO}_{2}$ p.c. requires 2050 carbon taxes in the ranges of $529-652$ and $970-1089 \mathrm{CHF} / \mathrm{tCO}_{2}$, respectively. These carbon taxes and the associated emission reductions translate to cumulative welfare losses in the ranges of $0.16-0.35 \%$ and $0.24-0.46 \%$, respectively, during the period between 2010 and 2050. These numbers suggest that ambitious emission targets can be achieved with relatively low economic consequences that are within the range of the expected benefits from keeping climate change under control.

When it comes to comparing different designs of carbon pricing, the results by the different CGE models vary. Small welfare gains can be achieved by taxing $\mathrm{CO}_{2}$ emissions from transport fuels at a lower rate than those from heating fuels as long as carbon taxes are not too high (i.e., in the early years of the analyzed time period and longer in the case of the less ambitious climate target). As time goes on and emissions reductions become more stringent, however, all models recommend uniform over differentiated carbon taxes.

Our group of models produces ranges of results that illustrate how different model structures and assumptions about the representation of technologies can lead to different outcomes. The range of results produced in this study should not, however, be interpreted as representative of the uncertainty about the future in general. Our study's range of carbon prices for a given policy scenario, for example, is mainly produced by different model assumptions leading to different abatement costs for a given abatement level. Meanwhile, the models have been calibrated to very similar assumptions about businessas-usual energy use and thus emission levels. Further accounting of the uncertainty about business-as-usual economic development until 2050 in general or energy use in particular would spread the range of carbon prices necessary to reach Switzerland's targets further.

\section{Acknowledgements}

Renger van Nieuwkoop and Marc Vielle provided us with their modeling results as well as descriptions of their respective models: CEPE-316 and GEMINI-E3. They and Philippe Thalmann gave feedback on earlier drafts of this manuscript and helped us improve the paper. Renger van Nieuwkoop helped facilitate an early exchange of modeling results by creating a web platform for collecting and graphically representing them.

\section{Authors' contributions}

AM compiled the results from the models with some help from FL. KR provided the results of the STEM model runs. AM and FL wrote the first draft of the paper, and all authors contributed to the writing of the consequent versions of it. All authors read and approved the final manuscript.

\section{Funding}

FL, AM, SR, and LB thank the financial support of SCCER CREST (Swiss Competence Center for Energy Research) funded by Innosuisse (Suisse Innovation Agency). KR thanks the financial support of SCCER Mobility (Swiss Competence Center for Energy Research - Efficient Technologies and Systems for Mobility) funded by Innosuisse.

\section{Availability of data and materials}

Descriptions of the models and their underlying data can be found according to the following list:

CEPE-HH For a description of the model and the required data, please consult the corresponding publication in this special issue (Landis, 2019).

CEPE-316 CEPE-316 is a customized version of the CEPE model, and a complete description of it is still missing as of the time of writing. Its author, Renger van Nieuwkoop, may be contacted under mailto:rengerv@ethz.ch.

CITE For a description of the model and the required data, please consult the corresponding publication in this special issue (Marcucci and Zhang, 2019).

GEMINI-E3 For a description of the model and the required data, please consult the corresponding publication in this special issue (Thalmann and Vielle, 2019).

STEM A description of the model and the required data can be found in a technical report by Kannan and Turton (2014).

Results from the model runs can be inspected and compared on the web site http://simlab.ethz.ch/1stSemp_results.php.

\section{Competing interests}

The authors declare that they have no competing interests.

\section{Author details}

${ }^{1}$ Center of Economic Research, ETH Zurich, Zürichbergstrasse 18, 8092, Zurich, Switzerland. ${ }^{2}$ Energy Economics Group, Paul Scherrer Institute, 5232, Villigen PSI, Switzerland.

Received: 13 July 2018 Accepted: 1 August 2019

Published online: 13 September 2019

\section{References}

Bernard, A., \& Vielle, M. (2008). GEMINI-E3 a general equilibrium model of international-national interactions between economy, energy and the environment. Computational Management Science, 5, 173-206.

BFE (2016). Schweizerische Gesamtenergiestatistik. Bern: Bundesamt für Energie (BFE).

BFS (2015). Szenarien zur Bevoelkerungsentwicklung der Schweiz. Neuchâtel: Bundesamt für Statistik (BFS).

Böhringer, C., Kosch, M., Landis, F., Rausch, S. (2019). Efficient and equitable policy design: taxing energy use or promoting energy savings? Energy Journal, 4(1), 73-105.

Böhringer, C., \& Müller, A. (2014). Environmental tax reforms in Switzerland a computable general equilibrium impact analysis. Swiss Journal of Economics and Statistics, 150(1), 1-21. 
Bovenberg, A.L., \& Goulder, L.H. (1996). Optimal environmental taxation in the presence of other taxes: general-equilibrium analyses. The American Economic Review, 86, 985-1000. ArticleType: research-article / Full publication date: Sep., 1996 / Copyright (C) 1996 American Economic Association.

Bretschger, L., \& Lin, Z. (2017). Nuclear phase-out under stringent climate policies: A dynamic macroeconomic analysis. Energy Journal, 38, 167-194.

Bretschger, L., Ramer, R., Schwark, F. (2011). Growth effects of carbon policies: Applying a fully dynamic CGE model with heterogeneous capital. Resource and Energy Economics, 33, 963-980. Special section: Sustainable Resource Use and Economic Dynamics.

Ecoplan (2012). Energiestrategie 2050 - volkswirtschaftliche Auswirkungen. Bern: Schlussbericht Bundesamt für Energie (BFE).

Federal Council (2015). Botschaft zum Verfassungsartikel über ein Klima- und Energielenkungssystem. BBI 2015 7877-7924.

Huntington, H.G., Weyant, J.P., Sweeney, J.L. (1982). Modeling for insights, not numbers: The experiences of the energy modeling forum. Omega, 10, 449-462.

IEA (2015). Energy technology perspective 2015: mobilising innovation to accelerate climate action. Paris: OECD/International Energy Agency.

Kannan, R., \& Turton, H. (2014). Switzerland energy transition scenarios: Development and application of the Swiss TIMES Energy system Model (STEM). PSI Bericht Nr. 14-06.

Kannan, R., \& Turton, H. (2016). Long term climate change mitigation goals under the nuclear phase out policy: The Swiss energy system transition. Energy Economics, 55, 211-222.

Karydas, C., \& Zhang, L. (2017). Green tax reform, endogenous innovation and the growth dividend. Journal of Environmental Economics and Management. https://doi.org/10.1016/j.jeem.2017.09.005.

Kriegler, E., Riahi, K., Bauer, N., Schwanitz, J., Petermann, N., Bosetti, V., Marcucci, A., Otto, S., Paroussos, L., Rao, S., Arroyo-Curras, T., Ashina, S., Bollen, J., Eom, J., Hamdi-Cherif, M., Longden, T., Kitous, A., Mejean, A., Sano, F., Schaeffer, M., Wada, K., Capros, P., van Vuuren, D., Edenhofer, O. (2015). Making or breaking climate targets: The AMPERE study on staged accession scenarios for climate policy. Technological Forecasting and Social Change, 9, Part A, 24-44.

Kriegler, E., Tavoni, M., Aboumahboub, T., Luderer, G., Calvin, K., Demaere, G., Krey, V., Riahi, K., Rosler, H., Schaeffer, M., Van Vuuren, D.P. (2013). What does the 2c target imply for a global climate agreement in 2020? The LIMITS study on Durban Platform scenarios. Climate Change Economics, 04 , 1340008 .

Landis, F. (2019). Cost distribution and equity of climate policy in Switzerland. Swiss Journal of Economics and Statistics. https://doi.org/10.1186/s41937019-0038-2.

Landis, F., Rausch, S., Kosch, M. (2018). Differentiated carbon prices and the economic cost of decarbonization. Environmental and Resource Economics, 70, 483-516.

Marcucci, A., \& Turton, H. (2012). Swiss energy strategies under global climate change and nuclear policy uncertainty. Swiss Journal of Economics and Statistics, 148, 317-345.

Marcucci, A., \& Zhang, L. (2019). Growth impacts of Swiss climate policies. Swiss Journal of Economics and Statistics.

Peters, J.C. (2016). The gtap-power data base: Disaggregating the electricity sector in the gtap data base. GTAP Journal of Global Economic Analysis, 1, 209-250.

Prognos (2012). Die Energieperspektiven fuer die Schweiz bis 2050. Basel: Prognos $A G$.

Romer, P. (1990). Endogenous technical change. The Journal of Political Economy, 98, S71-S102

Sceia, A., Altamirano-Cabrera, J.-C., Vielle, M., Weidmann, N. (2012). Assessment of acceptable Swiss post-2012 climate policies. Swiss Journal of Economics and Statistics, 148, 347-380.

Stern, N. (2007). The economics of climate change: The stern review. Cambridge: Cambridge University Press.

Swiss Federal Assembly (2018). New energy act. https://www.admin.ch/opc/ de/classified-compilation/20121295/index.html.

Swiss Federal Council (2013a). Botschaft zum ersten Massnahmenpaket der Energiestrategie 2050 und zur Volksinitiative fuer den geordneten Ausstieg aus der Atomenergie (Atomausstiegsinitiative). BBI 2013 7561-7756.

Swiss Federal Council (2013b). Ordinance on the reduction of CO2 emissions. https://www.admin.ch/opc/en/classified-compilation/20120090/index. html.
Thalmann, P., \& Vielle, M. (2019). Lowering CO2 emissions in the Swiss transport sector. Swiss Journal of Economics and Statistics. https://doi.org/ 10.1186/s41937-019-0037-3.

\section{Publisher's Note}

Springer Nature remains neutral with regard to jurisdictional claims in published maps and institutional affiliations.

\section{Submit your manuscript to a SpringerOpen ${ }^{\odot}$ journal and benefit from:}

- Convenient online submission

- Rigorous peer review

- Open access: articles freely available online

- High visibility within the field

- Retaining the copyright to your article

Submit your next manuscript at $>$ springeropen.com 